\title{
Applications of Nanostructured Carbon Materials in Constructions: The State of the Art
}

\author{
Shu-Nan Lu, ${ }^{1}$ Ning Xie, ${ }^{2,3}$ Li-Chao Feng, ${ }^{4}$ and Jing Zhong ${ }^{3}$ \\ ${ }^{1}$ College of Civil Engineering and Architecture, Harbin University of Science and Technology, Harbin 150080, China \\ ${ }^{2}$ School of Transportation Science and Engineering, Harbin Institute of Technology, Harbin 150001, China \\ ${ }^{3}$ School of Civil Engineering, Harbin Institute of Technology, Harbin 150001, China \\ ${ }^{4}$ School of Mechanical Engineering, Huaihai Institute of Technology and Jiangsu Marine Resources Development Research Institute, \\ Lianyungang 222005, China
}

Correspondence should be addressed to Ning Xie; xiening@hit.edu.cn

Received 30 September 2014; Accepted 20 April 2015

Academic Editor: Myoung-Woon Moon

Copyright (C) 2015 Shu-Nan Lu et al. This is an open access article distributed under the Creative Commons Attribution License, which permits unrestricted use, distribution, and reproduction in any medium, provided the original work is properly cited.

\begin{abstract}
The most recent studies on the applications of nanostructured carbon materials, including carbon nanotubes, carbon nanofibers, and graphene oxides, in constructions are presented. First, the preparation of nanostructured carbon/infrastructure material composites is summarized. This part is mainly focused on how the nanostructured carbon materials were mixed with cementitious or asphalt matrix to realize a good dispersion condition. Several methods, including high speed melting mixing, surface treatment, and aqueous solution with surfactants and sonication, were introduced. Second, the applications of the carbon nanostructured materials in constructions such as mechanical reinforcement, self-sensing detectors, self-heating element for deicing, and electromagnetic shielding component were systematically reviewed. This paper not only helps the readers understand the preparation process of the carbon nanostructured materials/infrastructure material composites but also sheds some light on the state-of-the-art applications of carbon nanostructured materials in constructions.
\end{abstract}

\section{Introduction}

Nanostructured carbon materials, including carbon nanotubes (CNTs), carbon nanofibers (CNFs), graphene (GR), graphene oxide $(\mathrm{GO})$, and fullerene, are promising elements that can be used in many practical areas [1-3]. One of the most important applications of the nanostructured carbon materials is using them to fabricate various composite materials including carbon/polymer [4], carbon/ceramic [5], carbon/cement [6], and carbon/metal [7] composites.

The infrastructure materials are the most commonly used materials in the modern civilization. Some studies demonstrated that, with the addition of nanostructured carbon materials, the overall performances of the infrastructure materials can be modified from various perspectives. It was believed that the nanostructured carbon materials will change the pore structures and hydration process of the cementitious materials and thus change the mechanical properties or functionalize the infrastructure materials.

Currently, the research on nanostructured carbon in infrastructure materials is burgeoning. In the former studies, rapid progress and improvements of advanced nanocarbon materials have led to numerous studies for construction materials. Nanotechnology has demonstrated its promising merits in empowering the development of infrastructures with mechanical reinforcement and many other functionalities. In this paper, the most recent studies on the preparation and applications of nanostructured carbon materials, including carbon nanotubes, carbon nanofibers, and graphene oxides, in constructions are presented.

\section{Preparation}

The final properties of the nanostructured carbon composites are determined by their fabrication process. Several methods 
were used to prepare the composites in the past decade. Thanks to its low cost, simplicity, and availability, high speed melt mixing process is the most widely used approach to prepare the composites. In this method, the nanostructured carbon material will be dispersed in a matrix material with a high shear mixing condition. The merit of the high speed melting mixing is that it can guarantee a good dispersion of the nanostructured carbon material in a matrix material; however, this process will damage the structure of the CNT, CNF, GR, or GO, which is another important factor governing the final properties of the composites. As a result, how to use low shear mixing speed to protect the structure of the carbon nanomaterials without sacrificing the dispersion condition is still a challenge to fabricate the composites.

Apart from the high speed melt mixing processing, the solution approach with help of sonication is another method to prepare the composites. In this process, the nanostructured carbon material will be dispersed in a liquid form solution by sonication before being mixed with the matrix. In addition, external cooling device has to be applied to avoid the temperature increase during the sonication process.

Unlike the applications in other areas, the applications of the nanostructured carbon materials in constructions have to satisfy some basic requirements before it can be widely accepted in the construction field. First, because the usage of the carbon nanomaterials will be extremely larger than other areas, the high speed melting mixing process in the field will not be realized as easy as in the lab. Second, for the construction applications, the cost of the composite fabrication has to be low before they can be widely applied. Accordingly, the quality and cost control are the top challenges for the applications of the nanostructured carbon materials in constructions.

Because the high speed melting mixing and solution methods are both not able to be easily realized in the construction fields, the surface treatment of the nanostructured carbon materials is becoming a promising approach to realize their good dispersion in a matrix material. In this process, various functional groups will be grafted on the surfaces of the carbon nanomaterials, and the compatibility between the matrix and the functional group will play a key role which decides the final properties of the composites. In some cases, the surface treatment was realized by oxidizing the surfaces of carbon nanomaterials by soaking them into acids at various temperatures followed by acylation. After that, the functional groups will be grafted on the surfaces of the carbon nanomaterials by the reaction between the carbon and the functional groups [14].

In the most recent years, the research of the carbon nanostructured composites in constructions has been focused on investigating effective dispersion methods of the carbon nanomaterials in the construction materials. Yu and Kwon [8] used two methods to realize the good dispersion of the CNT in cement matrix. The first one is called acid surface treatment method, which has been widely applied to disperse the CNTs in composites. In this process, the as-received CNTs were soaked in the sulfuric acid and nitric acid (with ratio of $3: 1$ ) for about $45 \mathrm{~min}$ at $110^{\circ} \mathrm{C}$. The reactive parts of the CNTs, namely, the ends and the defects, will be easily oxidized by the oxygen atoms in the acids. As a result, the surface of the CNTs will be grafted on negative charged groups and led to the good dispersion due to the electrostatic repulsions. The second method they used was the so-called noncovalent surface treatment of the CNTs. In this method, the CNTs were surface treated with polarized surfactant (sodium dodecyl sulfate) rather than acids. Unlike the acid treatment method, in which the CNT surfaces were grafted with functional groups, the surfactants were wrapped on the CNT surfaces and resulted in the dispersion of CNTs in solutions. After the dispersion treatment, the CNTs were mixed with cement (with 0.1 wt.\% of cement) to prepare the composites. Figure 1 shows the SEM image of the CNT/cement composites.

Another acids surface treatment method was applied to prepare well dispersed $\mathrm{CNT} /$ cement and $\mathrm{CNF} /$ cement composites [15]. In this study, the CNTs and CNFs were surface treated by soaking them in sulfuric acids and nitric acids (with ratio of $2: 1$ ) at $85^{\circ} \mathrm{C}$ for an hour with continuous magnetic stirring. After being washed and dried, the surface treated CNTs and CNFs were mixed with water and superplasticizer and sonicated for $20 \mathrm{~min}$ and $10 \mathrm{~min}$, respectively. After that, the CNT or CNF solutions were mixed with cement powder (with $0.1 \mathrm{wt} . \%$ and $0.2 \mathrm{wt} . \%$ of cement) to prepare the composites.

The preparation of well dispersed CNT/cement composites was also investigated by another study with surfactant surface treatment method [9]. In this study, various surfactants were used for the CNT dispersion. The CNTs were mixed with surfactants in aqueous solutions and sonicated at room temperature. Unlike the usual sonication tank with magnetic stirring, a sonicator with $500 \mathrm{~W}$ cup-horn high intensity cylindrical tip was used in this study. In addition to the types of surfactants, the concentration effect of the surfactants on the dispersion was investigated as well. It was found that the fracture strength of the composites was increasing followed by decreasing with increasing surfactant/CNT ratio. It was claimed that the optimum surfactant/CNT ratio is about 4.0. Figure 2 shows the effect of the surfactant concentration on the dispersion effect of the CNT in the cement matrix.

A few investigators have found the addition of the CNT/CNF in cement will largely affect the workability of the paste. As a result, how to maintain the workability of the $\mathrm{CNT} /$ cement composites became a top challenge. Collins et al. [16] reported the relationship between the dispersion, workability, and strength of CNT/cement composites, in which the CNTs were dispersed with concrete compatible surfactants, including air entraining agents, styrene butadiene rubber (SBS), polycarboxylates, calcium naphthalene sulfonate, and lignosulfonate formulations. It was found that the SBS and calcium naphthalene sulfonate admixtures lead to rapid agglomeration of CNTs; the air entraining agents dispersed CNTs in aqueous solutions very well but agglomeration occurred within days, while the polycarboxylate and lignosulfonate admixtures can provide good dispersion of CNTs in aqueous solutions as long as 9 days.

Meanwhile, Sobolkina divided the surfactant into anionic and nonionic types and investigated the dispersion effect 

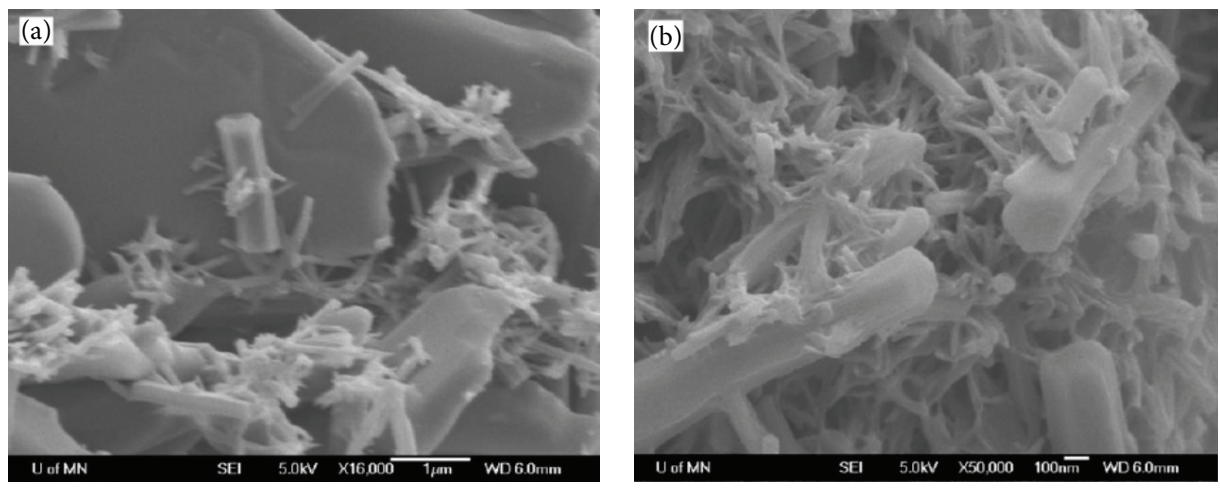

Figure 1: The SEM image of the CNT/cement composites [8].
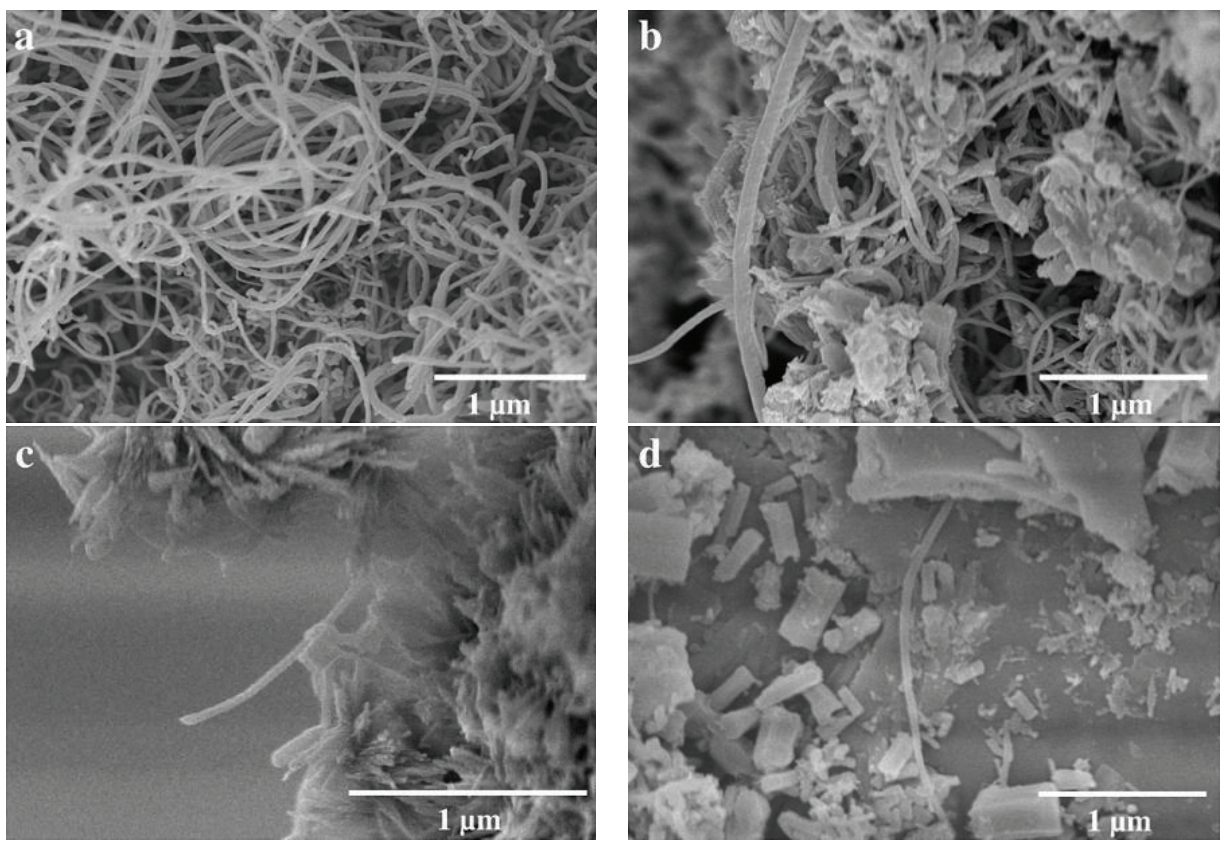

Figure 2: Effect of surfactant on the dispersion effect of the CNT in the cement matrix with CNT dosages of (a) $0 \%$, (b) 1.5 wt.\%, (c) 4.0 wt.\%, and (d) 6.25 wt.\% [9].

via UV-vis spectroscopy with sonication time and surfactant concentration as variables [17]. Different from KonstaGdoutos' study [9], it was found that the optimum surfactant/CNT ratio is $1: 1-1: 1.5$, and the best sonication time is $120 \mathrm{~min}$.

Other than the sonication time, the sonication energy was also used as parameter to evaluate the dispersion effect of $\mathrm{CNF} /$ cement composites [18]. The sonication energies of 2100,2800 , and $3500 \mathrm{~kJ} / \mathrm{l}$ were applied to dispersion effect of the CNF in the cement matrix. It was found that the composites with sonication energy of $2800 \mathrm{~kJ} / \mathrm{l}$ demonstrate the best performance.

Comparing with the dispersion process of CNT or CNF in water, the dispersion of GO in water is relatively easier and more stable. In general, the GO nanosheet will be prepared via modified Hummer's method [19]. In this method, the graphite powders were chemically oxidized and diluted in distilled water to prepare the well dispersed GO water solution. In addition to modified Hummer's method, the stable GO colloid suspension can be obtained by exfoliating the graphite oxide. This GO water solution can be used to prepare the GO/cement composite directly. Gong prepared the GO water solution with modified Hummer's method and fabricated the $\mathrm{GO} /$ cement composite [20], and Babak et al. [10] prepared the GO water solution via exfoliation method and prepared the GO/cement composites (shown in Figure 3). Both of their works agreed that the small amount of well dispersed GO addition will evidently enhance the performance of the cement material. Although the GO water solution is more stable than CNT's or CNF's, the study of $\mathrm{GO} /$ cement composite is still in its infancy stage and needs to be further systematically investigated in the future studies.

As another important infrastructure material, asphalt has been widely used as binder material for pavement construction, water proof layer at the building roofs, or crack sealer for pavement rehabilitations. Unlike the carbon/cementitious 


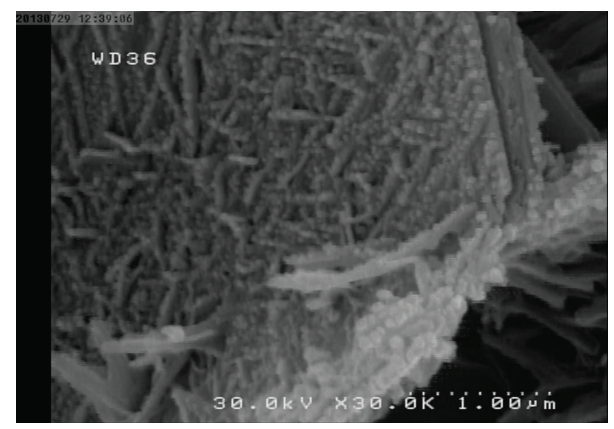

Figure 3: Cement matrix with addition of $1.5 \mathrm{wt} . \%$ GO [10].

composite, which has to be cured in a water environment, the carbon/asphalt composite, on the contrary, has to be prepared without water, because the water damage is one of the most important factors that reduce the durability of the asphalt material. Therefore, the dispersion of carbon nanostructured materials in asphalt is more difficult than in cementitious materials. To the best of our knowledge, a few effective ways have been developed to realize the good dispersion of carbon nanostructured materials in asphalt. Although the dispersion problem is still a bottle neck to prepare the nanocarbon/asphalt composite, the investigators are still working on this project with their full enthusiasm.

Because asphalt is a viscoelastic material, it is much easier to prepare the nanocarbon/asphalt composite via high speed melting mixing method. Recently, this method was used to prepare the CNT/bitumen composites [21-24]. Three types of mixers, namely, mechanical mixer, high shear mixer, and ultrasonic mixer, were used to evaluate the dispersion effect of the CNTs in the asphalt matrix. The mechanical mixer, whose motor rotation is a constant while the mixing time is a variable, and the high shear mixer, whose rotation rate is a variable, were used to prepare polymer modified asphalt. The specific designed mixer tip can guarantee a homogenous polymer distribution in asphalt matrix. Sonication mixer is another important mixer that can be used to prepare the nanocarbon/asphalt composite. One thing that has to be noted here is that this apparatus generates large amount of energy and increases the temperature of the composite; therefore, the cooling system might be needed during the mixing process $[23,25]$.

Combined with sonication and high shear mixing, Khattak developed a dispersion method and successfully prepared the well dispersed CNF/asphalt composite. In these studies, the CNFs were firstly thoroughly mixed with kerosene and followed by mixing with asphalt at $60^{\circ} \mathrm{C}$. Slowly raise the oil bath temperature to $150^{\circ} \mathrm{C}$ and keep mixing for $175 \mathrm{~min}$. During this process, the kerosene will be completely evaporated and the CNFs will be homogenously left in the asphalt matrix $[26,27]$.

In addition to surfactants and sonication, a new study demonstrates that the addition of appropriate quantity of silica fume has positive effect on the CNF dispersion in cement paste [28]. With normal sonication and surfactants treatment, the $\mathrm{CNF} /$ cement composites were prepared with/without addition of silica fume. It was found that the average dispersion value was 0.73 of the control specimen, while it increased to $0.83 \%$ with addition of silica fume ( silica/cement $=0.2)$.

\section{Applications}

3.1. Reinforcement. Mechanical properties are always the first priority that needs to be considered before the construction materials can be used in the fields. The application of carbon nanostructured materials as reinforcement has been widely studied in the past decade and accepted as an effective way to enhance the mechanical properties of the infrastructure materials [29-33].

The compressive and splitting tensile strength of the CNT reinforced cement paste were studied by Kumar et al. [34]. In this study, the CNTs were not surface treated. Before mixing with cement, the CNTs were only sonicated for $30 \mathrm{~min}$ to $4 \mathrm{~h}$ in water. The dosages of the CNTs were $0.5 \mathrm{wt} . \%$, $0.75 \mathrm{wt} . \%$, and $1.0 \mathrm{wt} . \%$ of the cement, the water/cement ratio was 0.4 , and the curing times were $7,28,60,90$, and 180 days. The testing results demonstrated that the samples cured for 28 days with $0.5 \mathrm{wt} . \%$ dosage of CNT have the best performance with compressive strength and splitting tensile strength enhancement of $15 \%$ and $36 \%$ comparing with the control samples.

By combining sonication and surfactants, $\mathrm{Hu}$ et al. considerably reduced the dosage of the CNT from $0.5 \mathrm{wt} . \%$ of cement to $0.1 \mathrm{wt} . \%$ [35]. It was found that, comparing with the control samples, the compressive strength of the CNT modified sample was not evidently enhanced while the fracture energy and fracture toughness were increased $26.2 \%$ and $11.4 \%$, respectively.

The rheological performance of the CNT reinforced cement slurries was investigated recently [36]. In this study, the lignosulfonate $(0.2 \%)$ was used as dispersant in the cement samples. It was found that the rheological performance and stability will not be changed with addition of CNT, while the flexural strength was increased about $15 \%$ with the dosage of $0.1 \%$ CNT.

Apart from the dosage, the effect of the aspect ratio of CNT on the mechanical properties was investigated as well [37]. Two types of CNTs with high aspect ratio (12503750) and low aspect ratio (157) were used to prepare the $\mathrm{CNT} /$ cement samples. The testing results showed that, with addition of $0.2 \mathrm{wt} . \%$ low aspect ratio CNT, the flexural strength of the 28 days samples increased about $269 \%$, and, with 0.1 high aspect ratio CNT, the flexural strength increased $65 \%$. Meanwhile, the optimized ductility enhancements of the 28 days samples were $86 \%$ and $81 \%$ with addition of 0.1 and 0.2 low aspect ratio CNTs, respectively.

The reinforcement on compressive and flexural strength of $\mathrm{CNF} /$ cement composites was investigated most recently $[38,39]$. In this study, the CNFs were dispersed in an aqueous solution with a new surfactant called methylcellulose (MC) by combining with sonication before mixing with cement. It was found that the addition of the CNF to the cement paste has negative effect on the compressive strength of 
the $\mathrm{CNF} /$ cement composite. However, the 28 days flexural strength was enhanced $21 \%$, and the optimized dosage of the CNF was $0.1 \mathrm{wt} . \%$ of cement.

There are some different voices arguing that the addition of the CNT or CNF has negative effects on the mechanical properties of cement paste $[15,16]$. It was claimed that extra ettringite will be formed on the acid treated CNT or CNF surfaces, which degraded the mechanical properties of the composites [15].

In addition to cementitious materials, the mechanical performances of the asphalt modified by CNT/CNF were also investigated during the past years $[21,26,27,39,40]$. With the addition of CNT from $0.3 \%$ to $1.2 \%$ weight percent of asphalt, the softening point, penetration depth, complex modulus, fatigue parameter, rutting parameter, and phase change angle of modified asphalt have all improved comparing with the control sample. However, continuously increasing the CNT content from $1.2 \%$ to $1.5 \%$ has little enhancement effect of the overall performances of the asphalt; therefore, it was claimed that the optimized dosage of the CNT in asphalt should be $1.2 \%$ weight of asphalt [39]. The rheological behavior of the CNT modified asphalt was reported recently $[25,40]$. It was found that the rheological performance of the asphalt materials can be largely influenced by the addition of CNTs. The viscosity increased about $10 \%$ with CNT dosage of $0.1 \%$, $25 \%$ with CNT dosage of $0.5 \%$, and above $100 \%$ with $1.0 \%$ CNT addition [24]. The fatigue testing results also show that the addition of CNT can considerably enhance the fatigue resistance of the asphalt material [40].

Apart from CNT/CNF modified cement composites, the GO addition is also another effective way to enhance the mechanical properties of cementitious materials. Although the results of this area are not quite fruitful, there still are some studies that show their mechanical reinforcement of the composite. A recent study demonstrated that the tensile and flexural strength were both increased with the dosage of GO increased from $0.01 \mathrm{wt} . \%$ to $0.03 \mathrm{wt} . \%$ and then decreased with the GO content being increased to $0.05 \mathrm{wt} . \%$. Comparing with the control samples, the tensile and flexural strengths of the samples with addition of $0.03 \mathrm{wt} . \% \mathrm{GO}$ increased $78.6 \%$ and $60.7 \%$, respectively. Meanwhile, the highest compressive strength was found in the samples with addition of $0.05 \mathrm{wt} . \%$ GO, which increased $47.0 \%$ by comparing with the samples without GO addition [41]. Similarly, Gong et al. [20] gives the results that with $0.03 \mathrm{wt} . \%$ of GO addition into the cement paste will increase the compressive and tensile strength over $40 \%$. This phenomenon has been further proven by Babak et al. [10]. In that study, it was found that, with $1.5 \mathrm{wt} . \%$ of GO in cement, the tensile strength was increased about 50\% comparing with the control samples.

Although some studies have demonstrated the overall performances of asphalt can be modified by adding CNT or CNF, the study of the asphalt material modified by GO is still very limited. In addition, there still are some bottle neck problems yet to be solved in the asphalt/nanostructured carbon material composites, such as how to effectively disperse the CNT or CNF in the asphalt, how to use GR or GO to modify the asphalt, and how the durability of the modified asphalt is. These questions will be the future study trends for the asphalt/nanocarbon composites.

3.2. Self-Sensing. Currently, the requirements for self-sensing have become an important characteristic to realize the smart constructions. The nanostructured carbon/cement composites, as a promising self-sensing infrastructure material, have been widely investigated in the past years $[2,8,12,42-46]$.

Technically, the realization of the self-sensing nanostructured carbon/cement composites is originated from evaluating the bulk electrical conductivity/resistivity variation that resulted from the external condition changes, including stress/strain, humidity, temperature, or gas environment, because the electrical properties of the nanostructured carbon/cement composites can be evidently changed with the change of external conditions. It can accurately reflect not only the external conditions of the constructions but also the inside conditions of the composites.

Han et al.s group did a great contribution in this area during the past decade. They systematically investigated the preparation, properties, and applications of the nanostructure carbon/cementitious composites and discussed their self-sensing performances from both academic and practical perspectives [11, 47-49].

Via testing the variation of its piezoresistive property, which can reflect the stresses status of the materials, the $\mathrm{CNT} /$ cement composite was prepared as self-sensing pavement to test the traffic flow [49]. The results showed that this composite has sensitive and stable response to the repeated compressive and impulsive loading, shown in Figure 4 [11]. One year later, they found that the piezoresistivity is largely governed by the water content of the composite [47]. The results indicated that the piezoresistivity values of $\mathrm{MWNT} / \mathrm{cement}$ composites with water contents of $0.1,1.3$, 3.3, 5.7, 7.6, and $9.9 \%$ are $0.60,0.61,0.73,0.68,0.34$, and $0.06 \mathrm{k} \Omega / \mathrm{MPa}$, respectively. Furthermore, they found that the piezoresistivity of the CNT/CNF cementitious composites is largely affected by the dispersant. Many surfactants, including sodium dodecyl sulfate (SDS), sodium dodecylbenzene sulfonate (NaDDBS), and methylcellulose, have been tested and proven to have negative effects on the piezoresistive property until a polycarboxylate superplasticizer was applied as the dispersant [50]. In light of the DC electrical resistivity measurement needing a prepower time to guarantee the resistance reaches its linear increasing stage, which is not convenient for testing, the AC electrical properties tests were developed to overcome the shortcomings of DC electrical resistivity measurements [43]. It was found that the capacitor charging and discharging effect on the pressure-sensitive responses of CNT/cement composites will be eliminated by $\mathrm{AC}$ electrical properties testing. In addition, it was claimed that a low-amplitude AC voltage is necessary to improve the pressure sensitivity of the $\mathrm{CNT} /$ cement composite.

Via piezoresistivity measurement, another study demonstrated the pressure sensitivity was different with different direction of loadings, namely, compressive and tensile forces [44]. In this study, it was confirmed that the electrical resistance increased with tensile loading, while it decreased 

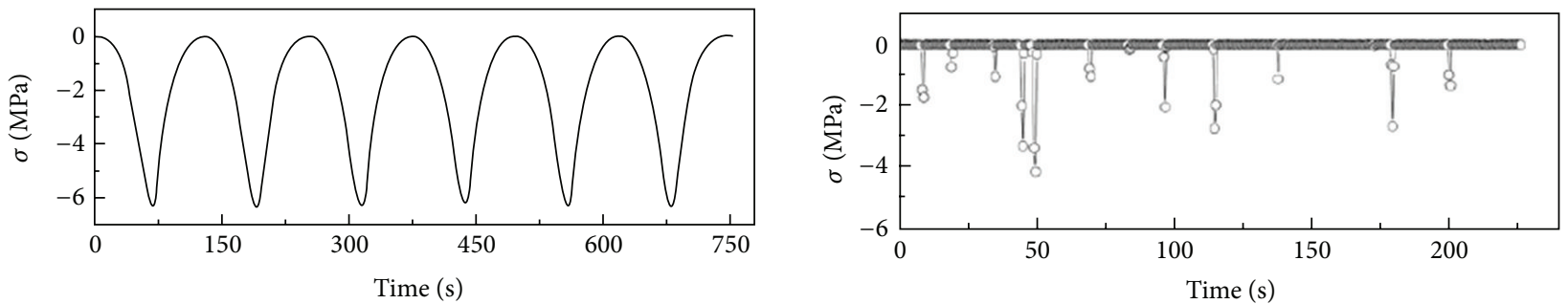

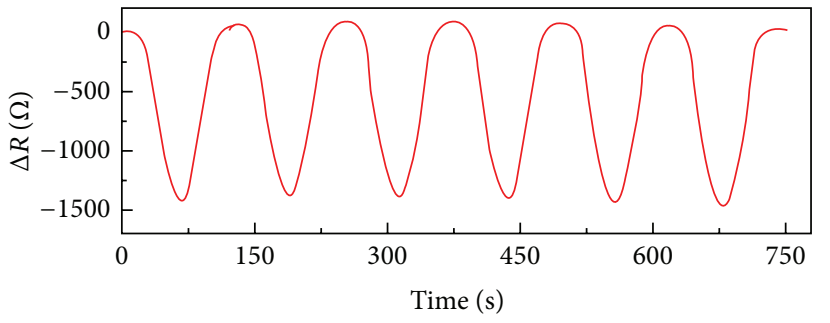

(a)

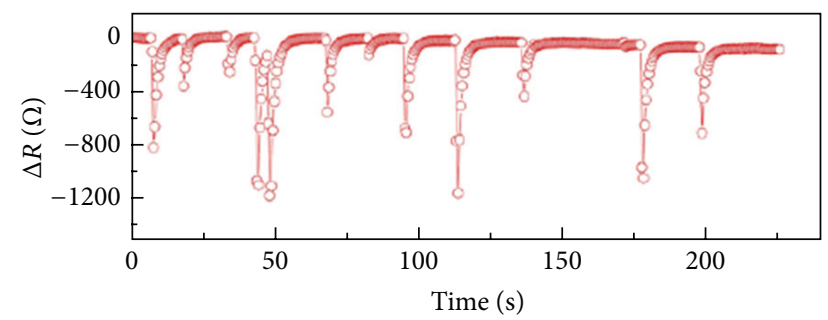

(b)

FIGURE 4: The electrical resistance as a function of the external loading of a self-sensing CNT/cement composite. (a) Corresponding to compressive loading of $6 \mathrm{MPa}$. (b) Corresponding to impulsive loading [11].

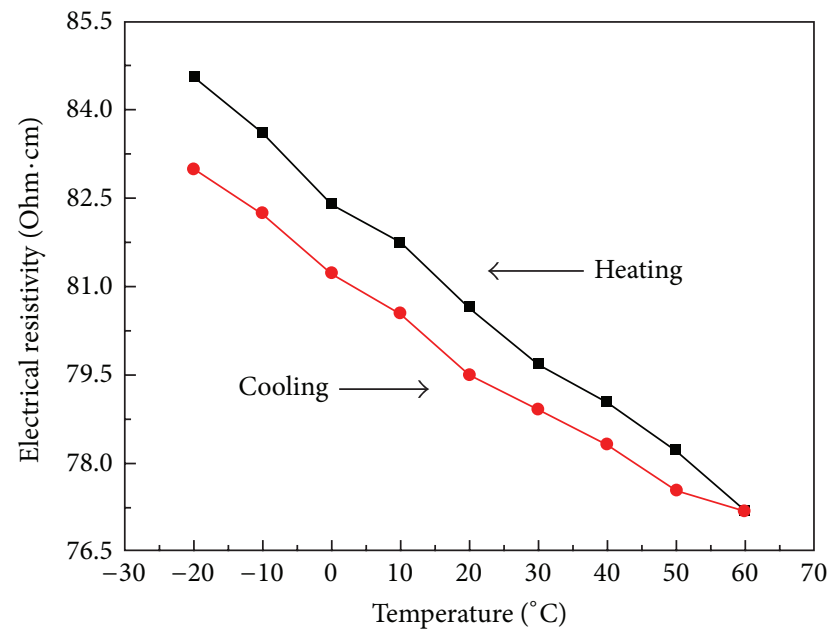

FIgURE 5: Heating and cooling plot of the electrical resistivity as a function of temperature with $0.4 \mathrm{wt} . \% \mathrm{CF}$ and $2.0 \mathrm{wt} . \% \mathrm{CNT}$ in a cement matrix [12].

with compression loading. In addition, the sensitivity was determined by the concentration of the CNT. Other than the loading directions, the effect of the water/binder ratio on the piezoresistivity of the $\mathrm{CNT} /$ cement composites was investigated as well. It was claimed that the low water/binder ratio has a positive effect on the piezoresistive sensitivity [46].

Other than the stress sensing, the temperature sensing property of the CNT modified cement composites was briefly investigated as well [12]. In that study, it was claimed that the addition of the CNT will clearly result in a temperature sensitivity. Figure 5 shows the heating and cooling relationship between the electrical resistivity and the temperature of the samples with $0.4 \mathrm{wt} . \%$ carbon fibers (CF) and $2.0 \mathrm{wt} . \% \mathrm{CNT}$ in the cement matrix. The temperature sensitivity coefficient enhanced with the CNT addition increased from $0.2 \mathrm{wt} . \%$ to $2.0 \mathrm{wt} . \%$, suggesting that the $\mathrm{CNT} / \mathrm{CF}$-cement composites could be applied as the thermistors to reflect the temperatures in concrete structures.

Most recently, the GO/cementitious composites were prepared and used as the self-sensing elements to monitor the infrastructures [51]. The compressive and tensile loading were able to be reflected by the piezoresistivity change of the $\mathrm{GO} / \mathrm{fly}$ ash geopolymeric composites. In these composites, the GO was easily reduced due to the strong alkaline environment of the fly ash geopolymer. With GO content increased from 0 to $0.35 \mathrm{wt} . \%$, the electrical conductivity of the GO/fly ash geopolymer composite increased from $0.77 \mathrm{~S} / \mathrm{m}$ to $2.38 \mathrm{~S} / \mathrm{m}$. The gauge factors, which are defined as $k=\Delta R / R_{0} \varepsilon$, were increased about $112 \%$ and $103 \%$, corresponding to tension and compression, respectively.

3.3. Self-Heating Deicing Pavement. Due to the huge negative impact of the deicing chemicals on the environment and the infrastructure materials [52], the self-heating deicing pavement has been investigated as a replacement of the deicing chemicals to control the ice and snow of the pavement surfaces in cold regions $[53,54]$. Using normal commercial carbon fibers as the heating elements to prepare the selfheating deicing concrete, including asphalt and cement, has been widely investigated in the past decade $[55,56]$. However, the cost for the electricity consumption of normal CF selfheating pavement is really high; the practical application of this technology has been largely limited.

Thanks to the decreasing fabrication cost of the nanostructured carbon materials, especially carbon nanofibers, they have been investigated as the heating elements to fabricate the self-heating deicing pavement. Due to its high chemical stability, magnificent electrical performances, and outstanding heating efficiency, it has been considered as an 


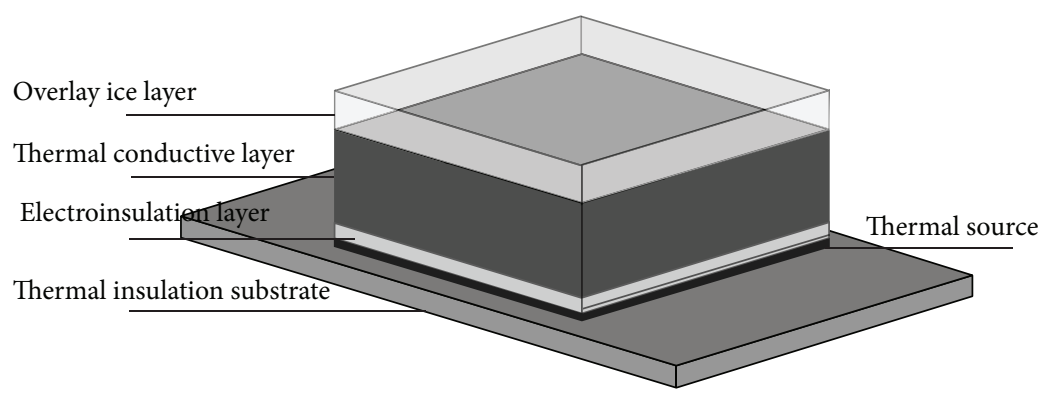

FIGURE 6: Schematic demonstration of a self-heating deicing pavement [13].

effective heating element to prepare the self-heating deicing pavement.

The deicing effects of the carbon nanofibers paper (CNFP) have been studied from numerical and experimental perspectives in recent years and demonstrated its high deicing efficiency. By using air temperature, wind speed, and thickness of the pavement or insulating layer as parameters, a finite element model was developed to evaluate the deicing effect of the CNFP [57] pavement. It was found that the temperature of the pavement equipped with CNFP can be raised up to $0^{\circ} \mathrm{C}$ with only 20 -VAC electrical charge in a relatively short time. In addition, the heating element embedment depth, surface convection conditions, and heating rate are the important factors affecting the heating responding time.

In addition to numerical studies, the experimental research was also carried out to investigate the heating efficiency of the self-deicing pavement $[13,58]$. As demonstrated in Figure 6, a multiple layer system was designed to realize the high efficiency self-heating deicing pavement. In this system, the thermal source layer was prepared with $\mathrm{CNF}$ /polymer composite, the thermal insulation substrate was made of epoxy polymer, the electroinsulation layer was the AIN ceramics, and the thermal conductive layer was prepared by $\mathrm{CNT} / \mathrm{cement}$ composite. The results show that the $\mathrm{CNT} /$ cement composite has a higher thermal conductivity $(2.83 \mathrm{~W} / \mathrm{m} \cdot \mathrm{K})$ than normal $\mathrm{CF} /$ cement composite $(1.3-$ $2.0 \mathrm{~W} / \mathrm{m} \cdot \mathrm{K})$ and plain cement concrete $(1.58 \mathrm{~W} / \mathrm{m} \cdot \mathrm{K})$. In addition, with a heat flux density of $600 \mathrm{~W} / \mathrm{m}^{2}$, the covered snow with depth of $20,30,40$, and $50 \mathrm{~mm}$ can be melted in $6000,6500,7500$, and 6800 seconds with surrounded temperatures of $-9.1,-9.2,-9.7$, and $-10^{\circ} \mathrm{C}$, respectively. The corresponding energy consumptions are 1.0, 1.12, 1.28, and $1.10 \mathrm{kWh} / \mathrm{m}^{2}$, respectively. By comparing the cost with the former studies, this multiple layer self-heating deicing pavement has a much lower cost $\left(0.05-0.11 \$ / \mathrm{m}^{2}\right)$ than $\mathrm{CF}$ or steel filled concrete. This experimental study has been compared with numerical study and the results show that the heat flux, air temperature, ice thickness, and wind speed have clear effects on the deicing time, which increases linearly with increasing ice thickness and decreases as a hyperbolic function of the heat-flux density and linearly with air temperature [58].
3.4. Electromagnetic Shielding. It has been widely accepted that the conductive concrete has the capability of electromagnetic (EM) wave absorption and can be used to build electromagnetic shielding infrastructures. Comparing with normal CF/cement composites, the CNT (CNF)/cement composites were considered with a higher EM absorption efficiency. Singh et al. [59] investigated the EM interference shielding performance of the CNT/cement composites. It was found that the shielding effectiveness (SE) was dominated by absorption rather than reflection and was higher than $28 \mathrm{~dB}$ in X-band (8.2-12.4 GHz) with 15 wt.\% CNT in cement concrete matrix. Due to the effective anisotropy energy and the interfacial polarization of the CNT/cement composite, the high efficient SE can be obtained by the EM wave scattering compared to other carbon/cement composites. Moreover, the dosage of the CNT in the cement matrix has a clear effect on the microwave absorption properties.

Another study demonstrated the EM absorption efficiency of the CNT/cement composite in a relatively low frequency with low CNT dosages. In addition, the effect of the thickness on the EM efficiency of the CNT/cement composite was studied as well [60]. In this study, it was found that the EM wave can be considerably absorbed in a frequency range of $2-8 \mathrm{GHz}$ with $0.6 \mathrm{wt} . \% \mathrm{CNT}$ and a $25 \mathrm{~mm}$ thickness of $\mathrm{CNT} /$ cement mortar samples. The highest peak of the reflection with value of $28 \mathrm{~dB}$ was observed at $2.9 \mathrm{GHz}$. Similar to other studies, it was found that the EM absorption capability increases with increasing CNT content. The reflection below $10 \mathrm{~dB}$ reached $7.1 \mathrm{GHz}$ with addition of $0.9 \mathrm{wt} . \% \mathrm{CNT}$.

The EM wave absorption capability in a wider frequency range was evaluated [61]. In this study, the dispersion of the CNT in cement matrix was improved with addition of the silica fume (SF). Unlike the above mentioned studies, this study claimed that the increase of the CNT dosage from $0.3 \mathrm{wt} . \%$ to $1.0 \mathrm{wt} . \%$ has little effect on the EM SE performance. However, with the synergistic addition of SF (20 wt.\%) and CNT (0.6 wt.\%), the CNT-SF/cement composites exhibited a good EM wave absorption performance in a wide range of frequency from $45 \mathrm{MHz}$ to $18 \mathrm{GHz}$. The best EM SE was observed at $0.94 \mathrm{GHz}, 1.56 \mathrm{GHz}$, and $2.46 \mathrm{GHz}$. In addition, comparing with the samples without addition of SF, the samples with 30 wt.\% SF and $1.0 \mathrm{wt} . \%$ CNT show the highest enhancement of EM SE with values of 111\%, 70\%, and 
$40 \%$ corresponding to $0.94 \mathrm{GHz}, 1.56 \mathrm{GHz}$, and $2.46 \mathrm{GHz}$, respectively.

3.5. Energy Harvesting. Although the investigations of the nanostructured carbon/cement as energy harvesting materials are very limited, a few studies were still carried out to test the piezoelectric and thermoelectric performances of the $\mathrm{CNT} /$ cement composites. Unlike the piezoresistivity, which is used to evaluate the sensing capability, the piezoelectric performance is used for the energy harvesting from converting the mechanical energy to the electrical energy of the CNT/cement composites. The piezoresistivity of the $\mathrm{CNT} /$ cement composites was realized by the backbones or tunneling channels changes of the CNT networks corresponding to external force field change which can result in an electrical conductivity change and reflect the external or internal conditions of the concrete infrastructures; however, the piezoelectricity was realized by changing the polarization status of the CNT/cement composites under external force field and generating an induced electrical field to realize the energy harvesting. Gong et al. [62] studied the piezoelectric performance of $\mathrm{CNT} /$ cement concrete mixed with lead zirconate titanate (PZT) powders. It was found that the piezoelectric realization temperature can be decreased from $120^{\circ} \mathrm{C}$ to room temperature with small amount of CNT addition ( $0.3 \mathrm{wt} . \%)$. The highest piezoelectric strain factors (d33) with value of $62 \mathrm{pC} / \mathrm{N}$ and the highest piezoelectric voltage factors (g33) with value of $60 \times 10^{-3} \mathrm{Vm} / \mathrm{N}$ can be obtained with 0.3 wt.\% CNT and 70 wt.\% PZT.

Other than piezoelectric performances, the thermoelectric performances of $\mathrm{CNT} /$ cement composites were also investigated recently. The Seeback coefficient of the CNT/cement composites with $0.5 \mathrm{wt} . \%$ CNT addition reached the highest thermoelectric power of $23.5 \mu \mathrm{V} / \mathrm{K}$ [63]. However, the temperature gradient between the two ends of the samples and the $Z_{t}$ value of the samples were not presented, which means the applications and the efficiency of transferring are still very limited. Although a few studies have demonstrated the thermoelectric performance of the carbon fiber/cement composites $[64,65]$, the thermoelectric performance of the nanostructured carbon/cement composites is still in its infancy stage. The $\mathrm{CNT} /$ cement, $\mathrm{CNF} /$ cement, or GR/cement composites can be used as potential thermoelectric devices in the future applications.

\section{Summary and Future Trends}

In this paper, the preparation methods of the nanostructured carbon/infrastructure materials composites, especially the dispersion methods of nanostructured carbon materials in the infrastructure materials matrix, were systematically reviewed. The high speed melt mixing, surface treatment, aqueous solution with surfactants, and sonication methods were presented to introduce the current preparation approaches. The surface treatment, aqueous solution with surfactants, and sonication methods were applied on the nanostructured carbon/cementitious materials composites, while the high speed melt mixing method was widely used in nanostructured carbon/asphalt composites. It was found that using surfactants or acid surface treatment to the nanostructured carbon materials is positive for their dispersion in cementitious materials, but different surfactants have different dispersion efficiency. Unfortunately, it is too early to draw conclusions of which surfactant is better than others because there are many influence factors determining various requirements of the composites. Another important factor that governs the dispersion of the carbon nanostructured materials in cementitious materials is the sonication energy. However, the investigation on this part is still very limited and should be further studied in the future studies. In addition to CNT and CNF, the investigation of the GO dispersion in a cementitious material matrix is still in an infancy stage. Many problems have not been solved so far to demonstrate an effective way of GO or GR dispersion in a cementitious material matrix.

The nanostructured carbon/cementitious composites can be used as self-sensing composites due to their capability to reflect external force field change via their specific piezoresistivity performance. As a self-sensing composite, the sensitivity and stability of the composites are a top challenge in the future studies. How to obtain a composite which has high piezoelectric sensitivity and stable performances in repeated loading cycles still needs to be systematically investigated.

For the thermoelectric converting investigation, the temperature gradient between the two ends and the $Z_{t}$ value of the composites were not systematically investigated. In addition, the investigations of the CNF/cement or GR/cement composites used as potential thermoelectric devices should be explored in the future investigations. For the piezoelectric constructions, the converting efficiency is the most important bottle neck problem that has to be solved before it can be widely applied in the fields.

\section{Conflict of Interests}

The authors declare that there is no conflict of interests regarding the publication of this paper.

\section{Acknowledgments}

This work was financially supported by the National Natural Science Foundation of China (51402074), the Lianyungang Scientific Plan-Industrial Program (CG1204), and the Six Talent Peaks Program of Jiangsu Province (ZBZZ-032).

\section{References}

[1] M. J. Hanus and A. T. Harris, "Nanotechnology innovations for the construction industry," Progress in Materials Science, vol. 58, no. 7, pp. 1056-1102, 2013.

[2] D. D. L. Chung, "Carbon materials for structural self-sensing, electromagnetic shielding and thermal interfacing," Carbon, vol. 50, no. 9, pp. 3342-3353, 2012. 
[3] S. J. Chen, F. G. Collins, A. J. N. Macleod, Z. Pan, W. H. Duan, and C. M. Wang, "Carbon nanotube-cement composites: a retrospect," The IES Journal Part A: Civil \& Structural Engineering, vol. 4, no. 4, pp. 254-265, 2011.

[4] Y. Liu and S. Kumar, "Polymer/carbon nanotube nano composite fibers-A review," ACS Applied Materials \& Interfaces, vol. 6, no. 9, pp. 6069-6087, 2014.

[5] L. S. Walker, V. R. Marotto, M. A. Rafiee, N. Koratkar, and E. L. Corral, "Toughening in graphene ceramic composites," ACS Nano, vol. 5, no. 4, pp. 3182-3190, 2011.

[6] S. Parveen, S. Rana, and R. Fangueiro, "A review on nanomaterial dispersion, microstructure, and mechanical properties of carbon nanotube and nanofiber reinforced cementitious composites," Journal of Nanomaterials, vol. 2013, Article ID 710175, 19 pages, 2013.

[7] S. J. Yan, S. L. Dai, X. Y. Zhang et al., "Investigating aluminum alloy reinforced by graphene nanoflakes," Materials Science and Engineering: A, vol. 612, pp. 440-444, 2014.

[8] X. Yu and E. Kwon, "A carbon nanotube/cement composite with piezoresistive properties," Smart Materials and Structures, vol. 18, no. 5, Article ID 055010, 2009.

[9] M. S. Konsta-Gdoutos, Z. S. Metaxa, and S. P. Shah, "Highly dispersed carbon nanotube reinforced cement based materials," Cement and Concrete Research, vol. 40, no. 7, pp. 1052-1059, 2010.

[10] F. Babak, H. Abolfazl, R. Alimorad, and G. Parviz, "Preparation and mechanical properties of graphene oxide: cement nanocomposites," The Scientific World Journal, vol. 2014, Article ID 276323, 10 pages, 2014.

[11] B. Han, X. Yu, and E. Kwon, "A self-sensing carbon nanotube/cement composite for traffic monitoring," Nanotechnology, vol. 20, no. 44, Article ID 445501, 2009.

[12] J. Zuo, W. Yao, X. Liu, and J. Qin, "Sensing properties of carbon nanotube-carbon fiber/cement nanocomposites," Journal of Testing and Evaluation, vol. 40, no. 5, pp. 838-843, 2012.

[13] H. Li, Q. Zhang, and H. Xiao, "Self-deicing road system with a CNFP high-efficiency thermal source and MWCNT/cementbased high-thermal conductive composites," Cold Regions Science and Technology, vol. 86, pp. 22-35, 2013.

[14] L. I. Nasibulina, I. V. Anoshkin, A. G. Nasibulin, A. Cwirzen, V. Penttala, and E. I. Kauppinen, "Effect of carbon nanotube aqueous dispersion quality on mechanical properties of cement composite," Journal of Nanomaterials, vol. 2012, Article ID 169262, 6 pages, 2012.

[15] R. K. Abu Al-Rub, B. M. Tyson, A. Yazdanbakhsh, and Z. Grasley, "Mechanical properties of nanocomposite cement incorporating surface-treated and untreated carbon nanotubes and carbon nanofibers," Journal of Nanomechanics and Micromechanics, vol. 2, no. 1, pp. 1-6, 2012.

[16] F. Collins, J. Lambert, and W. H. Duan, "The influences of admixtures on the dispersion, workability, and strength of carbon nanotube-OPC paste mixtures," Cement and Concrete Composites, vol. 34, no. 2, pp. 201-207, 2012.

[17] A. Sobolkina, V. Mechtcherine, V. Khavrus et al., "Dispersion of carbon nanotubes and its influence on the mechanical properties of the cement matrix," Cement and Concrete Composites, vol. 34, no. 10, pp. 1104-1113, 2012.

[18] Z. S. Metaxa, M. S. Konsta-Gdoutos, and S. P. Shah, "Carbon nanofiber cementitious composites: effect of debulking procedure on dispersion and reinforcing efficiency," Cement and Concrete Composites, vol. 36, no. 1, pp. 25-32, 2013.
[19] D. C. Marcano, D. V. Kosynkin, J. M. Berlin et al., "Improved synthesis of graphene oxide," ACS Nano, vol. 4, no. 8, pp. 48064814, 2010.

[20] K. Gong, Z. Pan, A. H. Korayem et al., "Reinforcing effects of graphene oxide on portland cement paste," Journal of Materials in Civil Engineering, vol. 27, A4014010, no. 2, pp. 1-6, 2014.

[21] A. A. Motlagh, A. Kiasat, E. Mirzaei, and F. O. Birgani, "Bitumen modification using carbon nanotubes," World Applied Sciences Journal, vol. 18, no. 4, pp. 594-599, 2012.

[22] M. J. Khattak, A. Khattab, H. R. Rizvi, and P. Zhang, "The impact of carbon nano-fiber modification on asphalt binder rheology," Construction and Building Materials, vol. 30, pp. 257-264, 2012.

[23] Z. Hasan, R. O. Kamran, F. Mohammad, G. Ahmad, and F. Hosein, "Evaluation of different conditions on the mixing bitumen and carbon nano-tubes," International Journal of Civil \& Environmental Engineering, vol. 12, pp. 53-59, 2012.

[24] E. Santagata, O. Baglieri, L. Tsantilis, and D. Dalmazzo, "Evaluation of self healing properties of bituminous binders taking into account steric hardening effects," Construction and Building Materials, vol. 41, pp. 60-67, 2013.

[25] H. Yao, Z. You, L. Li et al., "Rheological properties and chemical analysis of nanoclay and carbon microfiber modified asphalt with Fourier transform infrared spectroscopy," Construction and Building Materials, vol. 38, pp. 327-337, 2013.

[26] M. J. Khattak, A. Khattab, and H. R. Rizvi, "Characterization of carbon nano-fiber modified hot mix asphalt mixtures," Construction and Building Materials, vol. 40, pp. 738-745, 2013.

[27] M. J. Khattak, A. Khattab, P. Zhang, H. R. Rizvi, and T. Pesacreta, "Microstructure and fracture morphology of carbon nano-fiber modified asphalt and hot mix asphalt mixtures," Materials and Structures, vol. 46, no. 12, pp. 2045-2057, 2013.

[28] A. Yazdanbakhsh and Z. Grasley, "Utilization of silica fume to stabilize the dispersion of carbon nanofilaments in cement paste," Journal of Materials in Civil Engineering, vol. 26, no. 7, Article ID 06014010, 2014.

[29] A. Chaipanich, T. Nochaiya, W. Wongkeo, and P. Torkittikul, "Compressive strength and microstructure of carbon nanotubes-fly ash cement composites," Materials Science and Engineering A, vol. 527, no. 4-5, pp. 1063-1067, 2010.

[30] B. M. Tyson, R. K. Abu Al-Rub, A. Yazdanbakhsh, and Z. Grasley, "Carbon nanotubes and carbon nanofibers for enhancing the mechanical properties of nanocomposite cementitious materials," Journal of Materials in Civil Engineering, vol. 23, no. 7, pp. 1028-1035, 2011.

[31] A. Yazdanbakhsh, Z. Grasley, B. Tyson, and R. Abu Al-Rub, "Challenges and benefits of utilizing carbon nanofilaments in cementitious materials," Journal of Nanomaterials, vol. 2012, Article ID 371927, 8 pages, 2012.

[32] Z. S. Metaxa, J.-W. T. Seo, M. S. Konsta-Gdoutos, M. C. Hersam, and S. P. Shah, "Highly concentrated carbon nanotube admixture for nano-fiber reinforced cementitious materials," Cement and Concrete Composites, vol. 34, no. 5, pp. 612-617, 2012.

[33] R. Siddique and A. Mehta, "Effect of carbon nanotubes on properties of cement mortars," Construction and Building Materials, vol. 50, pp. 116-129, 2014.

[34] S. Kumar, P. Kolay, S. Malla, and S. Mishra, "Effect of multiwalled carbon nanotubes on mechanical strength of cement paste," Journal of Materials in Civil Engineering, vol. 24, no. 1, pp. 84-91, 2012. 
[35] Y. Hu, D. Luo, P. Li, Q. Li, and G. Sun, "Fracture toughness enhancement of cement paste with multi-walled carbon nanotubes," Construction and Building Materials, vol. 70, pp. 332338, 2014.

[36] J. N. Paula, J. M. Calixto, L. O. Ladeira et al., "Mechanical and rheological behavior of oil-well cement slurries produced with clinker containing carbon nanotubes," Journal of Petroleum Science and Engineering, vol. 122, pp. 274-279, 2014.

[37] R. K. Abu Al-Rub, A. I. Ashour, and B. M. Tyson, "On the aspect ratio effect of multi-walled carbon nanotube reinforcements on the mechanical properties of cementitious nanocomposites," Construction and Building Materials, vol. 35, pp. 647-655, 2012.

[38] B. Wang, T. Zhang, and Y. Han, "Reinforcement of surfacemodified multi-walled carbon nanotubes on cement-based composites," Advances in Cement Research, vol. 26, no. 2, pp. 7784, 2014.

[39] H. Ziari, H. Farahani, A. Goli, and S. S. Galooyak, "The investigation of the impact of carbon nano tube on bitumen and HMA performance," Petroleum Science and Technology, vol. 32, no. 17, pp. 2102-2108, 2014.

[40] E. Santagata, O. Baglieri, L. Tsantilis, and G. Chiappinelli, "Fatigue properties of bituminous binders reinforced with carbon nanotubes," International Journal of Pavement Engineering, vol. 16, no. 1, pp. 80-90, 2015.

[41] S. Lv, Y. Ma, C. Qiu, T. Sun, J. Liu, and Q. Zhou, "Effect of graphene oxide nanosheets of microstructure and mechanical properties of cement composites," Construction and Building Materials, vol. 49, pp. 121-127, 2013.

[42] F. Azhari and N. Banthia, "Cement-based sensors with carbon fibers and carbon nanotubes for piezoresistive sensing," Cement and Concrete Composites, vol. 34, no. 7, pp. 866-873, 2012.

[43] B. Han, K. Zhang, X. Yu, E. Kwon, and J. Ou, "Electrical characteristics and pressure-sensitive response measurements of carboxyl MWNT/cement composites," Cement and Concrete Composites, vol. 34, no. 6, pp. 794-800, 2012.

[44] B. Andrawes and L. Y. Chan, "Compression and tension stresssensing of carbon nanotube-reinforced cement," Magazine of Concrete Research, vol. 64, no. 3, pp. 253-258, 2012.

[45] A. L. Materazzi, F. Ubertini, and A. D’Alessandro, "Carbon nanotube cement-based transducers for dynamic sensing of strain," Cement and Concrete Composites, vol. 37, no. 1, pp. 211, 2013.

[46] H. K. Kim, I. S. Park, and H. K. Lee, "Improved piezoresistive sensitivity and stability of CNT/cement mortar composites with low water-binder ratio," Composite Structures, vol. 116, pp. 713719, 2014.

[47] B. Han, X. Yu, and J. Ou, "Effect of water content on the piezoresistivity of MWNT/cement composites," Journal of Materials Science, vol. 45, no. 14, pp. 3714-3719, 2010.

[48] B. Han, X. Yu, and J. Ou, "Multifunctional and smart carbon nanotube reinforced cement-based materials," in Nanotechnology in Civil Infrastructure, pp. 1-47, Springer, Berlin, Germany, 2011.

[49] B. Han, K. Zhang, T. Burnham, E. Kwon, and X. Yu, "Integration and road tests of a self-sensing CNT concrete pavement system for traffic detection," Smart Materials and Structures, vol. 22, no. 1, Article ID 015020, 2013.

[50] B. Han, K. Zhang, X. Yu, E. Kwon, and J. Ou, "Fabrication of Piezoresistive CNT/CNF Cementitious Composites with Superplasticizer as Dispersant," Journal of Materials in Civil Engineering, vol. 24, no. 6, pp. 658-665, 2012.
[51] M. Saafi, K. Andrew, P. L. Tang et al., "Multifunctional properties of carbon nanotube/fly ash geopolymeric nanocomposites," Construction and Building Materials, vol. 49, pp. 46-55, 2013.

[52] X. Shi, N. Xie, K. Fortune, and J. Gong, "Durability of steel reinforced concrete in chloride environments: an overview," Construction and Building Materials, vol. 30, pp. 125-138, 2012.

[53] S. Yehia, C. Y. Tuan, D. Ferdon, and B. Chen, "Conductive concrete overlay for bridge deck deicing: mixture proportioning, optimization, and properties," ACI Materials Journal, vol. 97, no. 2, pp. 172-181, 2000.

[54] T. Yang, Z. J. Yang, M. Singla, G. Song, and Q. Li, "Experimental study on carbon fiber tape-based deicing technology," Journal of Cold Regions Engineering, vol. 26, no. 2, pp. 55-70, 2012.

[55] S. Wu, L. Mo, Z. Shui, and Z. Chen, "Investigation of the conductivity of asphalt concrete containing conductive fillers," Carbon, vol. 43, no. 7, pp. 1358-1363, 2005.

[56] H. Zhao, Z. Wu, S. Wang, J. Zheng, and G. Che, "Concrete pavement deicing with carbon fiber heating wires," Cold Regions Science and Technology, vol. 65, no. 3, pp. 413-420, 2011.

[57] X.-M. Zhou, Z. J. Yang, C. Chang, and G. Song, "Numerical assessment of electric roadway deicing system utilizing emerging carbon nanofiber paper," Journal of Cold Regions Engineering, vol. 26, no. 1, pp. 1-15, 2012.

[58] H. Li, Q. Zhang, and H. Xiao, "Analytic investigations of CNFPbased self-deicing road system on the deicing performance," Cold Regions Science and Technology, vol. 103, pp. 123-132, 2014.

[59] A. P. Singh, B. K. Gupta, M. Mishra, A. Chandra, R. B. Mathur, and S. K. Dhawan, "Multiwalled carbon nanotube/cement composites with exceptional electromagnetic interference shielding properties," Carbon, vol. 56, pp. 86-96, 2013.

[60] B. Wang, Z. Guo, Y. Han, and T. Zhang, "Electromagnetic wave absorbing properties of multi-walled carbon nanotube/cement composites," Construction and Building Materials, vol. 46, pp. 98-103, 2013.

[61] I. W. Nam, H. K. Kim, and H. K. Lee, "Influence of silica fume additions on electromagnetic interference shielding effectiveness of multi-walled carbon nanotube/cement composites," Construction and Building Materials, vol. 30, pp. 480-487, 2012.

[62] H. Gong, Y. Zhang, J. Quan, and S. Che, "Preparation and properties of cement based piezoelectric composites modified by CNTs," Current Applied Physics, vol. 11, no. 3, pp. 653-656, 2011.

[63] J. Zuo, W. Yao, and K. Wu, "Seebeck effect and mechanical properties of carbon nanotube-carbon fiber/cement nanocomposites," Fullerenes, Nanotubes and Carbon Nanostructures, vol. 23, no. 5, pp. 383-391, 2015.

[64] J. Wei, L. Hao, G. He, and C. Yang, "Enhanced thermoelectric effect of carbon fiber reinforced cement composites by metallic oxide/cement interface," Ceramics International, vol. 40, no. 6, pp. 8261-8263, 2014.

[65] J. Wei, Z. Nie, G. He, L. Hao, L. Zhao, and Q. Zhang, "Energy harvesting from solar irradiation in cities using the thermoelectric behavior of carbon fiber reinforced cement composites," RSC Advances, vol. 4, no. 89, pp. 48128-48134, 2014. 

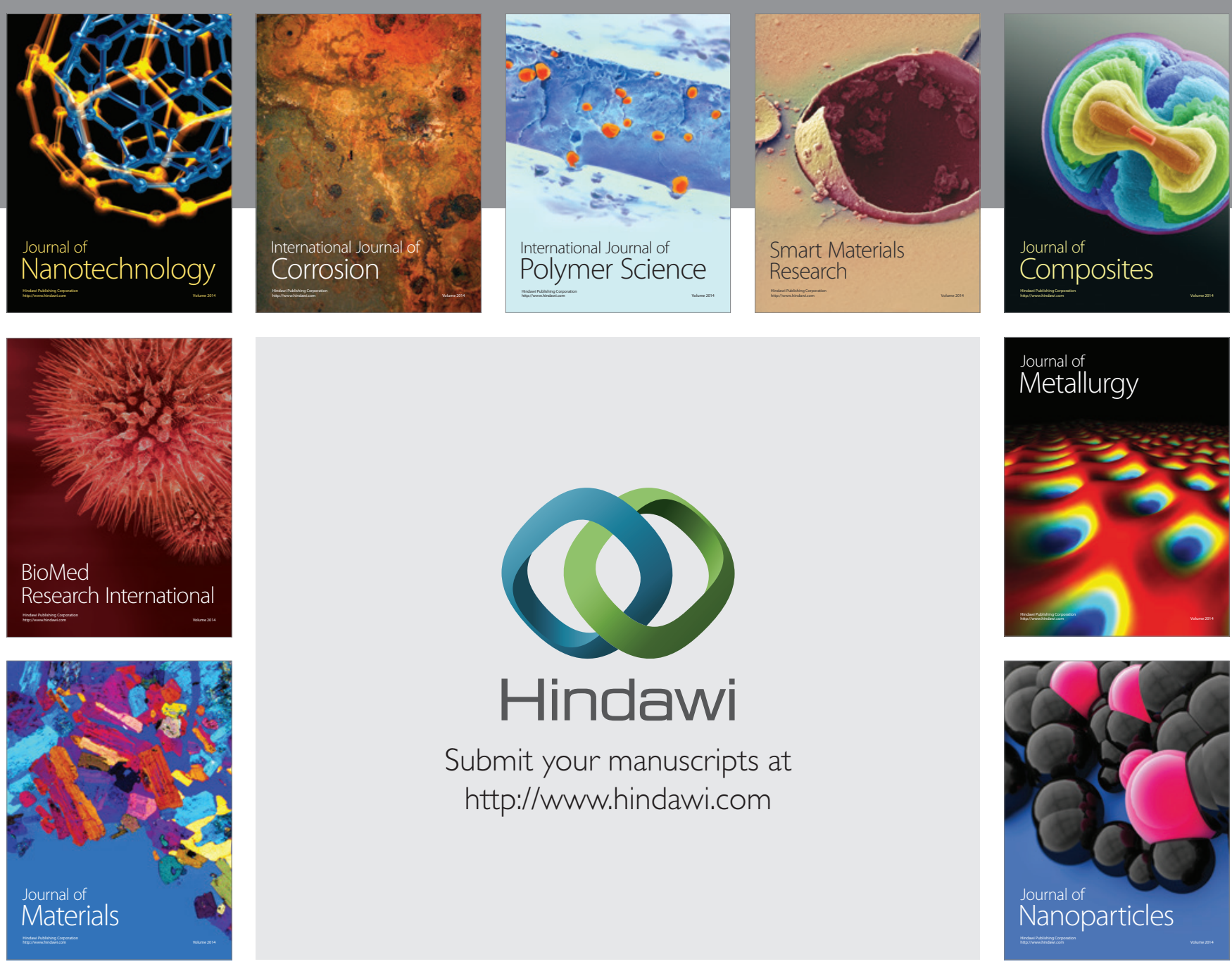

Submit your manuscripts at http://www.hindawi.com
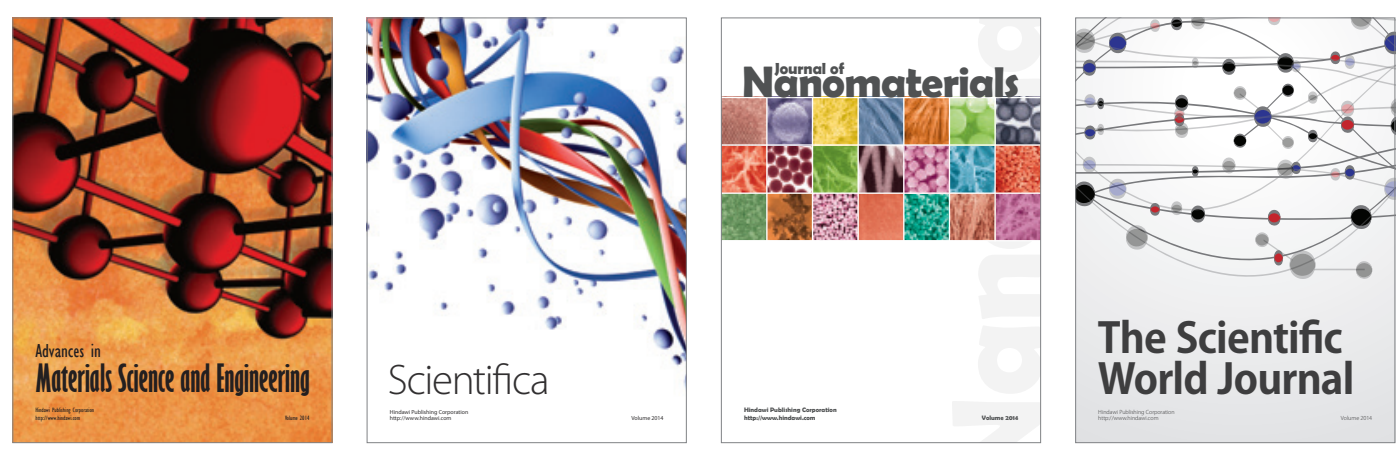

\section{The Scientific World Journal}
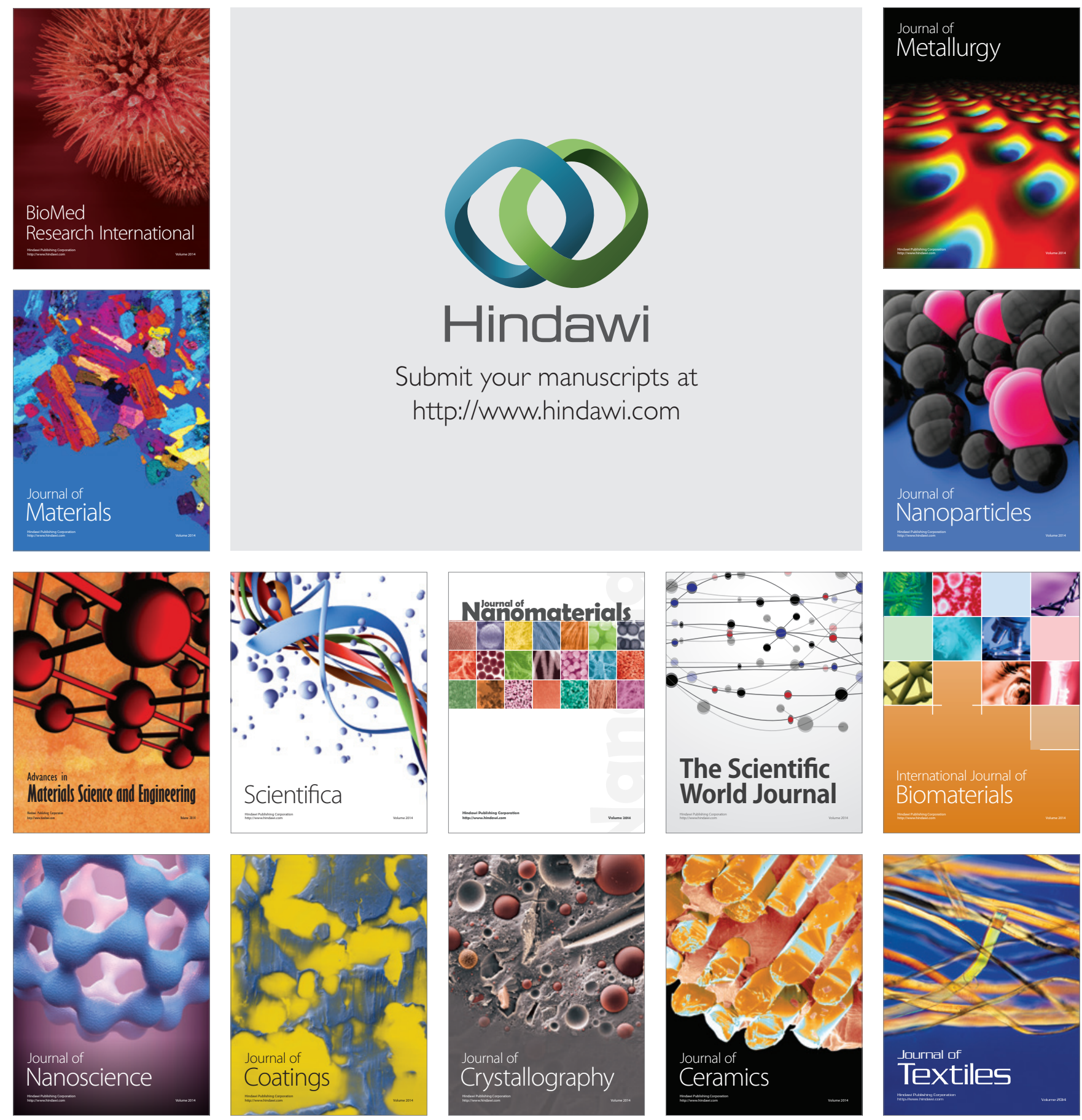